\title{
O AMICUS CURIAE COMO INSTRUMENTO DE AFIRMAÇÃO DOS DIREITOS FUNDAMENTAIS PROCESSUAIS NO NOVO CÓDIGO DE PROCESSO CIVIL
}

Carolina Moraes Migliavacca*

\section{A PERSPECTIVA CONSTITUCIONAL DO NOVO CÓDIGO DE PROCESSO CIVIL}

Temos um Novo Código de Processo Civil. Apesar de novo, a Lei 13.105 de 16 de março de 2015 espelha muitos valores, conceitos e preceitos que há muito já vinham sendo constantemente defendidos e aplicados em nossa sistemática processual civil. Pode-se mesmo afirmar que desde o nascimento da Constituição da República Federativa Brasileira de 1988, seus princípios fundamentais irradiaram-se para as demais áreas do direto público e privado, atingindo, como não poderia deixar de ser, o ramo do direito processual civil (JOBIM; MACEDO, 2015, p. 43).

A parte inaugural do novo código ilustra a valorização dos princípios fundamentais constitucionais não apenas na interpretação e aplicação dos dispositivos recém editados, mas também no próprio texto expressamente estampado no diploma legal. 0 Código de Processo Civil, que em 1973 foi concebido em um clima

* Doutoranda em Teoria da Jurisdição e Processo pela PUC-RS. Mestre em Teoria da Jurisdição e Processo pela PUC-RS. Especialista em Direito Processual Civil pela PUC-RS. Professora Universitária da Faculdade de Direito do Centro Universitário Metodista do Sul. Advogada. 
de certa autoafirmação da tutela de direitos individuais, enaltecendo conceitos processuais por vezes cerrados em si mesmos, agora recebe uma roupagem mais utilitária, objetiva e focada nos preceitos fundamentais constitucionais. Munido de uma muito bem-vinda reverência às balizas constitucionais, o novo Código de Processo Civil traz um parte geral destinada a, preambularmente, dedicar-se às normas fundamentais do processo civil.

Trata-se de um código voltado aos expressos vetores da cooperação (artigos 6ำ 191, 357, § 3o etc.), do contraditório (arts. 7ํㅗ 9ำ 487, § único, etc.) e da participação do cidadão como garantia constitucional processual. Este último ingrediente para a elaboração de um Código de Processo Civil mais adequado à nossa tão massificada e pluralizada sociedade (cenário tão diferente do que recebeu o Código de Processo Civil de 1073, tão atento às tutelas individuais) foi concebido em uma ideia de defesa de direitos difusos e coletivos, porém hoje se aplica também a demandas cuja discussão diga respeito a direitos individuais com carga representativa. Nesse sentido, a ideia já vinha insculpida na própria gênese constitucional: “a ação também é uma garantia para a participação do cidadão na reivindicação da tutela dos direitos difusos e coletivos na gestão da coisa pública. A ação, nesta perspectiva, é ligada à ideia de democracia participativa, sendo indispensável para o incremento da participação direta do povo no poder e para a realização de direitos imprescindíveis para a justa organização da sociedade. 0 particular pode participar, ainda que indiretamente, na busca de tutela dos direitos imprescindíveis para a justa organização da sociedade" (MARINONI; CANOTILHO; MENDES; SARLET; STRECK, 2013, p. 367).

Válida, ainda, a lição de Flávio Tartuci, ao denominar princípio da socialidade a nova onda processual, pois "um dos escopos da nova codificação foi o de superar o caráter individualista e egoísta da codificação anterior. Nesse contexto, a palavra eu é substituída por nós" (TARTUCE, 2015, p. 5). 


\section{A PRESENÇA DO AMICUS CURIAE NO SISTEMA PROCESSUAL CIVIL BRASILEIRO ANTES DA EDIÇÃO DO NOVO CÓDIGO DE PROCESSO CIVIL}

Apesar de o artigo 138, do Novo Código de Processo Civil, se tratar de inegável avanço na abertura democrática do processo civil individual ou coletivo, e em todos os graus de jurisdição, o amicus curiae não é novidade no sistema processual civil brasileiro. Não identificamos, até o advento do novo código, um diploma legal que atribua às mais diversas intervenções anômalas previstas em nosso ordenamento a denominação amicus curiae. Entretanto, a doutrina e a jurisprudência há muito se encarregaram de atribuir esta nomenclatura a determinadas formas interventivas que não se enquadram nas modalidades usuais dos artigos 50 a 80 e 499 (terceiro prejudicado), do código de 1973.

A Lei n. 6.385/76, a qual cria a autarquia federal conhecida como Comissão de Valores Mobiliários (CVM), é vista como uma das fontes legais que permite a intervenção desta entidade como amicus curiae. 0 artigo 31 da lei determina que "nos processos judiciários que tenham por objetivo matéria incluída na competência da Comissão de Valores Mobiliários, será esta sempre intimada para, querendo, oferecer parecer ou prestar esclarecimentos, no prazo de quinze dias a contar da intimação".

0 mesmo se refere às demais leis que preveem intervenções anômalas e fundadas em interesse institucional, e não propriamente jurídico na causa, tais quais: Lei 8.884/94, que prevê a intervenção do Conselho Administrativo de Defesa Econômica (CADE); artigo 49, parágrafo único, da Lei 8.906/94, a qual institui o Estatuto da Ordem dos Advogados do Brasil (OAB); a Lei 9.279/96,que regula a proteção de propriedade industrial e permite que o Instituto Nacional da Propriedade Industrial (INPI) apresente opinião nas ações de nulidade de patente; artigo 5ํ da Lei 9.469/97, que permite a intervenção da União Federal "nas causas em que figurarem, como autoras ou rés, 
autarquias, fundações públicas, sociedades de economia mista e empresas públicas federais"; a Lei 9.868/99, que regula a Ação Direta de Inconstitucionalidade (ADI), Ação Declaratória de Constitucionalidade (ADC) e Arguição de Descumprimento de Preceito Fundamental (ADPF), e que permite, em seu artigo 7ํㅡ, parágrafo $2^{\circ}$, que o relator admita a manifestação de órgãos ou entidades; por fim, e não que aqui se esgote o rol de diplomas legais que preveem estas formas anômalas de intervenção, não se pode descuidar dos arts. 543-A, § 6ㅇ e 543-C, § 4으, do CPC de 1973, que permitem a consulta a terceiros nos incidentes de averiguação de repercussão geral nos Recursos Extraordinários e recursos repetitivos, nos Recursos Especiais.

Não há dúvidas para a doutrina que tais previsões são, sim, caracterizadas como um expresso recebimento do amicus curiaeno sistema processual civil brasileiro (CABRAL, 2004, p. 24). Para a jurisprudência, há muito também não se questiona a presença do instituto, como se vê nos seguintes precedentes: ADI 4071,do Relator Ministro Menezes Direito. Tribunal Pleno, julgado em 22 de abril de 2009; ADI 3773, do Relator Ministro Menezes Direito. Tribunal Pleno, julgado em 04 de março de 2009; ADI 3857,do Relator Ministro Ricardo Lewandowski. Tribunal Pleno, julgado em 18 de dezembro de 2008; ADI 3772,do Relator Ministro Carlos Britto. Tribunal Pleno, julgado em 29 de outubro de 2008; ADI 2501, do Relator Ministro Joaquim Barbosa. Tribunal Pleno, julgado em 04 de setembro de 2008; ADI 3378, do do Relator Ministro Carlos Britto. Tribunal Pleno, julgado em 09 de abril de 2008.

Portanto, a inclusão do art. 138 no Novo Código de Processo Civil é uma verdadeira afirmação de instituto que já habita o ordenamento jurídico pátrio, tal qual a reprodução expressa dos princípios norteadores fundamentais constitucionais do processo civil na parcela inaugural da Parte Geral do novo código. 


\section{A POSITIVAÇÃO DO AMICUS CURIAE NO NOVO CÓDIGO DE PROCESSO CIVIL COMO INSTRUMENTO DE APLICAÇÃO DOS DIREITOS FUNDAMENTAIS PROCESSUAIS}

E sem dúvida a previsão de possibilidade de intervenção do amicus curiae nos processos judiciais em primeiro e segundo graus, qualificando-se este como "pessoa natural ou jurídica, órgão ou entidade especializada, com representatividade adequada", é verdadeira afirmação e aplicação concreta dos preceitos fundamentais constitucionais em uma nova ótica e valorização da função do processo civil. E, por que não, pode-se falar em uma função social do direito processual civil, na medida em que cada vez mais o Judiciário atua em respostas para questões relevantes, de repercussão coletiva e atinente a valores constitucionais com uma imediatidade que a atividade legislativa por vezes não comporta.

Para que se chegue em um cenário de adequação e afirmação dos princípios fundamentais processuais por meio da intervenção do amicus curiae nos processos judiciais, vale relembrar com brevidade a evolucão do papel do Direito Processual Civil na sociedade brasileira. Esta análise pode iniciar na herança lusitana absorvida pelo Brasil, que mesmo conquistando a sua independência política, manteve as normas processuais das ordenações Filipinas.Promulgadas em 1603, as Ordenações Filipinas desenharam um processo civil calcado no princípio do dispositivo, sendo o impulso das partes a única força motriz do processo. Diante da rigidez e do formalismo vinculados às fases processuais, não havia espaço para maiores inovações ou para a assimilação de novos institutos vinculados ao processo civil (CINTRA; GRINOVER; DINAMARCO, 2006, p. 111).

O Regulamento 737, editado como Código de Processo Comercial de 1850, pode ser apontado como o primeiro código processual elaborado no Brasil. Muito embora as Ordenações Filipinas ainda regessem as normas gerais de Direito Processual 
Civil, o Regulamento voltou-se para o processo estritamente de matéria comercial. Sua principal característica era a valorização da técnica processual e da economia dos atos procedimentais. Posteriormente, formou-se uma consolidação das Ordenações e das leis extravagantes, a Consolidação de Ribas, em 1871 (ARRUDA ALVIM, 2006, p. 53).

Acompanhando as principais reformas processuais, as fases históricas do Direito Processual Civil brasileiro podem ser identificadas da seguinte maneira: (a) fase de passagem do abstrato ao concreto: assimila-se que o avanço do abandono de um modelo abstrato e formalista do processo civil foi em direção de um processo mais voltado para a efetividade. Agregam-se procedimentos sumários, atendimento a tutelas de urgência, enfim, instrumentos disponíveis para a efetivação e realização do direito material; (b) do plano nacional ao plano internacional: notou-se, na evolução do Direito Processual Civil, um enaltencimento da colaboração internacional, criando-se procedimentos para a efetivação de tutelas extravagantes aos limites territoriais nacionais; e, finalmente, a (c) passagem do plano individual ao plano social, em que se percebe uma preocupação maior com a repercussão do resultado da prestação jurisdicional no âmbito coletivo, e não somente restrito às partes litigantes. Verificando-se que a decisão advinda de uma ação pode trazer reflexos a grupos, categorias e classes específicas, lança-se mão de procedimentos coletivos e instrumentos capazes de inserir a participação coletiva social no processo civil, ainda que individual (CINTRA; GRINOVER; DINAMARCO, 2006, p. 137-138).

Arruda Alvim aponta, inclusive, para um paralelo entre esta nova ordem social do Direito Processual Civil e os ditames do Processo Civil clássico. 0 autor refere que a separação rígida entre as funções do processo civil (função cognitiva restrita ao processo de conhecimento; função cautelar, ao processo cautelar; tutela de direitos coletivos ao processo coletivo, enfim) é uma 
das características intrínsecas da concepção clássica deste ramo do Direito. 0 mesmo ideal responsável pela inserção de medidas para a efetivação do direito material mediante a fusão das funções processuais com outras fases procedimentais impulsionou o questionamento da individualização do processo civil. Arremata o autor: "se, durante muito tempo, reivindicações de segmentos sociais desprotegidos (...) passam despercebidas, mercê do avultado dos problemas engendrados, tais reclamos não mais poderiam ser ignorardos" (ARRUDA ALVIM, 2006, p. 7477). Ainda que muitos anos após esta caminhada valorativa para o direito processual civil, percebe-se que a participação do amicus curiae está em absoluta sintonia com este ideal, assim como, evidentemente, o art. 138 do Novo Código de Processo Civil.

Afinal, não são apenas modificações concretas e pontuais da própria teoria geral do processo civil que podem ser apontadas como reflexo da evolução desta ciência ao longo das mudanças histórico-políticas, tanto no Brasil, como em outros países. 0 fundamento de direcionamento do processo civil unicamente para a solução de conflitos individuais é, a priori, incompatível com o instituto do amicus curiae. E foi exatamente esta concepção que evoluiu, reconhecendo-se que, paralelamente à tutela de direitos cujos efeitos se dão unicamente no campo particular dos litigantes, deve-se atentar, também, a direitos com repercussão coletiva, ou mesmo assuntos que interessam a coletividade, ainda que não se fale em uma ação coletiva.

Diz-se que esta concepção macro da função do Direito Processual Civil tem repercussão não limitada às demandas coletivas porque ela deve fazer parte do próprio modelo procedimental conduzido pelas partes e, principalmente, pelo juiz. Podem-se identificar, como elementos deste novo ideal procedimental: (a) o abandono da ideia de que o juiz deve agir como mero espectador do litígio, tomando uma postura mais ativa inclusive na determinação dos elementos que constituirão a fase instrutória; 
(b) a apreciação livre, pelo juiz, de todas as provas que advém no processo e (c) a distinção entre o limite objetivo da lide, delineado pelas partes, e o conteúdo do processo que fica sob a fiscalização do juiz (ARRUDA ALVIM, 2006, p. 82).

0 novo modelo do processo civil enquanto relação jurídica em contraditório traz conceito que pode ser aplicado para a participação de indivíduos além dos limites subjetivos da lide, especialmente em decorrência da "perspectiva política (o contraditório, garantia democrática de participação dos sujeitos na formação da decisão judicial, que polariza o procedimento, ângulo externo de apreciação do processo)" (MITIDIERO, 2005, p. 144). Conclui-se que a evolução do Direito Processual Civil e a sua atual concepção aponta para ampliação do diálogo entre o juiz e as partes, o que leva ao alargamento dos limites para a atuação probatória (inclusive de ofício), entrando em sintonia com o instituto do amicus curiae.

Uma das ideias que fundamentam a aceitação do instituto reside na noção de encontro entre o campo das relações privadas, quando são sujeitos privados que atuam como amici curiae,e do direito público, mais especificamente no ramo do processo civil. A dicotomia existente entre as esferas público e privada é marcante no ordenamento jurídico brasileiro.

O movimento de preocupação estatal com a observação dos direitos fundamentais no campo dos particulares, por intermédio dos instrumentos do Direito Público, encontra início na Constituição alemã de 1949. Neste diploma, consta a determinação de que os direitos fundamentais ali enunciados são diretamente aplicáveis, ou seja, o Poder Judiciário possui um poder-dever de aplicar imediatamente as normas definidoras de direitos e garantias fundamentais, assegurando-lhes sua plena eficácia. (SARLET, 2006, p. 280).

É marcante, também, a oposição à Constituição de Weimar (1919), que continha normas programáticas que não vinculavam o 
Poder Legislativo (FACCHINI, 2006, p. 29). Evidentemente, a carta alemã difere da Constituição da República Federativa Brasileira, vez que a última deixa aberta a possibilidade de interpretação sistemática, em que "cada preceito deve ser visto como parte viva do todo, eis que apenas no exame de conjunto tende a ser melhor equacionado qualquer caso" (FREITAS, 2004, p. 71-72). Assim, não só os poderes públicos se encontram vinculados aos direitos fundamentais, mas também os sujeitos privados.

0 estado atual encontra um sentido moderno para a "constitucionalização do direito privado", mas também o ramo do direito processual, que é público, carecia relembrar a sua relevância para a afirmação e aplicação concreta destes direitos fundamentais.

A premissa acima exposta conduz à inevitável conclusão de que a presença positivada do amicus curiaeno novo Código de Processo Civil também encontra fundamento na democratização dos poderes constituídos. Nessa seara, toma-se por base a teoria do agir comunicativo de Habermas como um dos canais de comunicação que devem existir entre a sociedade e a jurisdição constitucional. Trata-se de uma ampliação do conceito da democracia deliberativa a uma ética de discurso.

E como é necessário desenhar nosso futuro, porém com os olhos atentos ao que já se construiu no passado, cabe relembrar que Habermas parte do pressuposto de que a democracia é produto de um ambiente social de liberdade e de igualdade, promovido pelo estado social de direito. Sua teoria também aponta para o fato de que, no debate público, não será outro o resultado senão o desequilíbrio e o controle de massas por uma minoria privilegiada, caso não exista igualdade de condições para os sujeitos participantes do debate público. Para atingir a verdadeira instituição da democracia com a participação diversificada dos vários representantes da sociedade no debate público, o teórico sugere um procedimento específico: em primeiro lugar, para sociedades complexas e pluralistas, como as grandes coletivida- 
des contemporâneas, deve ser excluída a concepção material de legitimidade, substituindo-se por um processo democrático de elaboração de leis, dentro da ideia de "consenso procedimental". Para tanto, Habermas conta com cidadãos que contribuem não apenas com a razão, mas também com a sua vontade de contribuir com a cooperação social. 0 procedimento encontra sustentação nos princípios da universalização, que prevê a necessidade para toda a norma válida de que os seus eventuais resultados indesejáveis, resultantes de sua observância universal, sejam aceitos pela coletividade, a fim de satisfazer os interesses dos indivíduos como um todo; e da "ética do discurso", que prevê a possibilidade de toda a norma válida receber aceitação por cada indivíduo se existisse a possibilidade de um discurso prático (HABERMAS, 1989, p. 143-149). A intervenção do amicus curiae, ao menos no que diz respeito à comunicação entre o Poder Judiciário, mediante os processos judiciais, com certos representantes da sociedade, contém embasamento teórico justamente nesta ideia de possibilidade de um diálogo que confirma a democracia, com a devida observação às regras procedimentais.

O Poder Judiciáriofigura como portal para este diálogo entre a sociedade e o poder estatal. Atualmente, pode-se afirmar que o papel do Judiciário, aliás, tem recebido realce especial principalmente em função do aumento da complexidade dos sistemas políticos (FACCHINI, 2007, p. 139), bem como a sociedade civil tem-se desenvolvido de maneira mais dinâmica e expandido, de forma mais rápida, para problemas fáticos antes não pensados pelo Estado (BAUMAN, 1999, p. 63).

Eugênio Facchini Neto aponta para duas razões básicas para o aprofundamento do papel do Judiciário na sociedade atual, e qualifica-as como irreversíveis. São elas: (a) a mudança da estrutura do sistema jurídico, observada a partir da segunda metade do século XX, e que tinha por objetivo alcançar o Estado constitucional de direito e (b) a alteração da estrutura política 
com o desenvolvimento deste Estado social, em consequência do maior intervencionismo do Estado na economia e na sociedade (FACCHINI, 2007, p. 140).

Atualmente, o Judiciário encontra-se dissociado da tradicional ideia de que o Estado apenas desempenhava duas funções (protetiva - dos atos lícitos) e repressiva (dos ilícitos), sendo razoável afirmar que as decisões advindas do Judiciário - as munidas de repercussão geral, com certeza - devem encontrar consenso com a situação atual da sociedade, com o aparato instrumental oferecido pela realidade social e política do momento presente. Assim, afirma-se que o Judiciário é figurante ativo na democracia participativa.

É exatamente nesta ideia que a abertura do Direito Processual Civil ao instituto do amicus curiae, cujo berço é estrangeiro, encontra fundamento. Trata-se de uma participação democrática que ocorre fora dos contornos do Poder Legislativo. Aliás, participação mais do que justificada neste momento em que o próprio Código de Processo Civil de 2015 enaltece a força dos precedentes como regra por meio de tantos institutos e modalidades, tal qual o incidente de assunção de competência. 0 instituto possibilita um meio de influenciar e reivindicar as decisões estatais-judiciais com a legítima participação de terceiros representantes da sociedade (CABRAL, 2004, p. 10). O Processo Civil, enquanto ramo do Direito Público, é um dos elementos imprescindíveis à administração da resolução de conflitos e, mediante o Poder Judiciário, exerce a função de "fiador de um regime democrático" (BAPTISTA DA SILVA, 2004, p. 319).

Isso justifica a aceitação de instrumentos que tornem possível a participação também dos sujeitos privados alheios à limitação subjetiva original do processo na prestação judicial.As decisões judiciais, ainda que proferidas em processos individuais, podem "assumir relevância prática para centenas, milhares, talvez milhões de almas que nem sequer precisam haver tomado conhe- 
cimento da existência do pleito (...). Ao consagrar esta ou aquela tese jurídica, a decisão vai somar-se às anteriores" (BARBOSA MOREIRA, 2004, p. 30).

Se ao Direito Processual Civil cabe, enquanto função social, solucionar atritos entre princípios constitucionais, equilibrando interesses sociais, econômicos, culturais e políticos (OLIVEIRA, 2004, p. 1), a participação do amicus curiae nos processos judiciais nada mais é do que a legitimação de representantes da sociedade, ou de alguma parcela sua, para a participação na solução de conflitos atinentes a interesses da coletividade.

Com efeito, a positivação que o amicus curiaerecebeu em nosso novo código implica a observação de diversos princípios constitucionais que estão vinculados ao ramo do Direito Processual Civil. 0 acesso à justiça, encontrado no artigo 5o $\mathrm{XXXV,CRFB,}$ apesar de estar focada na abertura do sistema judiciário para as partes litigantes em si, faz parte de "um sistema jurídico moderno e igualitário que pretende garantir, e não apenas proclamar os direitos de todos" (CAPPELLETTI; GARTH, 1988, p. 12), portanto também é exigível por terceiros institucionalmente interessados, ainda mais em se tratando de ações cujos efeitos atingem toda a sociedade, como são aquelas munidas de repercussão geral. 0 sistema processual civil brasileiro, portanto, ao permitir a abertura do processo ao acesso do amicus curiae condiz com a intenção de permitir a efetiva colaboração e exercício da cidadania no ramo do Judiciário, que recebe cada vez maiores responsabilidades sociais e assume, mais e mais, um caráter criador de regras.

A manutenção do instituto, portanto, amplia o conhecimento dos magistrados sobre o objeto julgado e, mais do que isso, possibilita um debate relevante e público sobre as matérias de maior repercussão nacional. 0 resultado é a democratização da jurisdição e o controle da sociedade sobre os atos judiciais, que é, aliás, um dos fundamentos do princípio da publicidade, artigos 5ㅜㅡ, LX e 93, IX, CRFB (ALVIM, 2007, p. 60). Da mesma forma, refina 
a interação do juiz com a realidade social, política e econômica atual, pois o mantém consciente sobre as informações técnicas específicas e relativas ao objeto da lide, bem como o ponto de vista do grupo mediante oitiva de suas entidades representativas.

0 amicus curiae já encontrava fundamentos, portanto, no ordenamento jurídico, mesmo antes da redação do art. 138, do Novo Código. 0 princípio da cooperação, consequente do contraditório, positivado no artigo 5ํㅡ, LV, CRFB, exige dos sujeitos processuais a tomada de novas medidas, sendo que cabe ao magistrado o estímulo ao debate processual como forma de acertar a decisão final processual ao maior convencimento do sentenciante (RICCI, 2006, p. 497). Ao juiz cabe deixar a posição de inércia coordenar proativamente o processo, em decorrência, até mesmo, dos seus poderes instrutórios - já que as manifestações dos amici trazem dados técnicos valiosos para a compreensão do objeto em lide. Nesse aspecto, o princípio do livre convencimento do juiz também vai ao encontro da abertura do sistema processual civil ao instituto do amicus curiae, pois o Direito deve harmonizarse com a realidade da sociedade, e não afastá-la do processo, e alguns dos instrumentos para tanto é a interpretação da lei e a avaliação da prova.

Sendo assim, inegável a qualificação do amicus curiae como um dos principais canais para a comunicação entre o processo e a sociedade, e este é o seu principal fundamento. Não somente o instituto já encontrava respaldo no ordenamento processual civil brasileiro antes mesmo de projetado um novo código, como ele se adéqua perfeitamente à valorização expressa de preceitos fundamentais constitucionais trazida em nosso novo código.

\section{REFERÊNCIAS}

ALVARO DE OLIVEIRA, Carlos Alberto. 0 processo civil na perspectiva dos direitos fundamentais. Processo e constituição. Rio de Janeiro: Forense, p. 1-15, 2004. 
ALVIM, Artur da Fonseca. Garantia constitucional da publicidade dos atos processuais. Constituição, jurisdição e processo: estudos em homenagem aos 55 anos da Revista Jurídica. MOLINARO, Carlos Alberto; PORTO, Sérgio Gilberto; MILHORANZA, Mariângela (Coord.). Sapucaia do Sul: Notadez, 2007.

ARRUDA ALVIM. Manual de direito processual civil. v.1, 10.ed, São Paulo: Revista dos Tribunais, 2006.

BAPTISTA DA SILVA, Ovídio. Processo e ideologia. O paradigma racionalista. Rio de Janeiro: Forense, 2004.

BARBOSA MOREIRA, José Carlos. Temas de direito processual. São Paulo: Saraiva, 2004.

BAUMAN, Zygmunt. Globalização, as consequências humanas. Rio de Janeiro: Jorge Zahar Editor, 1999.

CABRAL, Antonio do Passo. Pelas asas de hermes: a intervenção do amicus curiae, um terceiro especial. Uma análise dos institutos interventivos similares - o amicus e o Vertreter dês öffentlichen Interesses. Revista de Processo. São Paulo: Revista dos Tribunais, n. 11, p. 9-41, 2004.

CAPPELLETTI, Mauro; GARTH, Bryant. Acesso à justiça. Porto Alegre: Fabris, 1988.

CINTRA, Antonio Carlos de Araújo; GRINOVER, Ada Pellegrini; DINAMARCO, Cândido Rangel. Teoria geral do processo. 22.ed, São Paulo: Malheiros, 2006.

FACCHINI NETO, Eugênio. 0 judiciário no mundo contemporâneo. Revista da ajuris, n. 108, Porto Alegre: Ajuris, p. 139-165, dezembro de 2007.

FACCHINI NETO, Eugênio. Reflexões historico-evolutivas sobre a constitucionalização do direito privado. Constituição, direitos fundamentais e direito privado. SARLET, Ingo Wolfgang (Org.). 2.ed. Porto Alegre: Livraria do Advogado, p. 13-61, 2006.

FREITAS, Juarez. A interpretação sistemática do direito. 4.ed. São Paulo: Malheiros, 2004.

HABERMAS, Jürgen. Consciência moral e agir comunicativo. Traduzido por Guido A. de Almeida. Rio de Janeiro: Tempo Brasileiro, 1989.

JOBIM, Marco Félix; MACEDO, Elaine Harzheim. Das normas fundamentais do processo e o projeto de novo código de processo civil brasileiro: repetições e inovações. In: Desvendando o novo CPC. Porto Alegre: Livraria do Advogado, 2015. 
MARINONI, Luiz Guilherme. Comentários à Constituição do Brasil. Coord.: SARLET, Ingo Wolfgang; STRECK, Lenio Luiz; MENDES, Gilmar Ferreira. São Paulo: Saraiva, 2013.

MITIDIERO, Daniel. Colaboração no processo civil. Pressupostos sociais, lógicos e éticos. São Paulo: Revista dos Tribunais, 2009.

MITIDIERO, Daniel. Elementos para uma teoria contemporânea do processo civil brasileiro. Porto Alegre: Livraria do advogado, 2005.

RICCI, Edoardo F. Princípio do contraditório e questões que o juiz pode propor de ofício. Processo e constituição. Estudos em homenagem ao professor José Carlos Barbosa Moreira. FUX, Luiz; NERY JR., Nelson; WAMBIER, Teresa Arruda Alvim (Coord.). São Paulo: Editora Revista dos Tribunais, p. 495-499, 2006.

SARLET, Ingo Wolfgang. A eficácia dos direitos fundamentais. 6.ed. Porto Alegre: Livraria do Advogado, 2006.

TARTUCE, Flávio. 0 novo CPC e o direito civil. Rio de Janeiro: Forense, 2015. 